\title{
Detection of High Addictive Habits Circulating Office in Charge of Private Pharmacy Institutions in Pune University India (Evidence Based Study of Late Report Office in Charge to College)
}

\author{
Rahul Hajare* \\ Post Doc Fellow, Indian Council of Medical Research, India \\ Received: June 20, 2018; Published: July 03, 2018 \\ *Corresponding author: Rahul Hajare, Post Doc Fellow, Indian Council of Medical Research, New Delhi, India
}

\begin{abstract}
We need to start doing things that do not accomplish anything in particular immediately. This has urgent to understand punctuality and reputation of the professional course. This will not wait until has aged early. Reporting late by the head of the organization epidemic has a merging irregularities practising disease that can damage any part of the time table at any time, any gender. It has force that creates inconsistent autoantibodies that attack and destroy healthy educational environment and college institutions. Taken granted head of organization has a serious leading cause that can affect anyone. It has most often diagnosed in experience principal who has dependent on alcohol power politics to retirement men women head of the organization, between the ages of 40 to post occupied retirement. While the cause has known, it has a self granted in which irregular adrenal syndrome pharmaceutical adrenal insufficiency (Addison's disease) inadequate system attacks healthy cells by pre planning casual pathway that can potentially damage many parts of the body. There has been some known cure for adrenal deficiency epidemic and treatment in early stage. Laboratory studies can detect abnormalities that may indicate TB cancer. When a TB has been suspected, imaging tests such as X-rays, computed tomography (CT), magnetic resonance imaging (MRI), ultrasound, and fiber-optic endoscopy examinations help doctors determine the TB location and size.
\end{abstract}

Abbreviations: CT: Computed Tomography; MRI: Magnetic Resonance Imaging

\section{Introduction}

There has little doubt that India's private pharmacy principal institute has contributing to its irregular practices [1,2]. India's government has aiming to eradicate alcohol dependent principal pharmacy institute from India by 2020, five years ahead of the global alcohol dependent pharmacy institutions principal elimination target of 2030. It has a worthy goal that will bring significant health and economic benefits: rises in Indians in 2016 -- more than 183 every day, with most deaths occurring among economically productive adults. A health technician analyses blood samples for extended level of alcohol in blood testing in a high-tech lab. To make the goal achievable, India must look beyond improving diagnosis and treatment and attack the many factors that have driving alcohol dependent principal pharmacy institutions. A winwin strategy for the government will be taking strong action to eradicate unethical practices of principal of the institutors use by superpower of AICTE, Government of India and alteration capacity of statutory body Pharmacy Act, 1948 passed by the Parliament for zero alcohol principal $[3,4]$.
The Pharmacy education and profession in India up to graduate level is regulated by the PCI a statutory body under the Ministry of Health and Family Welfare of India. The evidence base has only increased since then. Studies consistently find that alcohol dependency increases the risk of developing active institutions, has linked with more severe presentations and longer duration of bad habit followed by institutional staffs and translated in college students, increasing the risk of degradation health of institutions and has associated with a higher rate of relapse. Research confirms those risks also increase among non-smokers principals exposed to second hand tobacco smoke, mainly middle age principal or early join principal's institutions $[5,6]$. There has little doubt that India's alcohol epidemic in corporate culture of pharmacy institutions has contributing to its cell degradation and damage DNA. Over 103 million adults (70+ years old) and 625,000 younger children (10 to 14) use tobacco + less alcohol each day. Our most recent alcohol Atlas notes that 7.9 per cent of TB (Figures $1 \& 2$ ). 


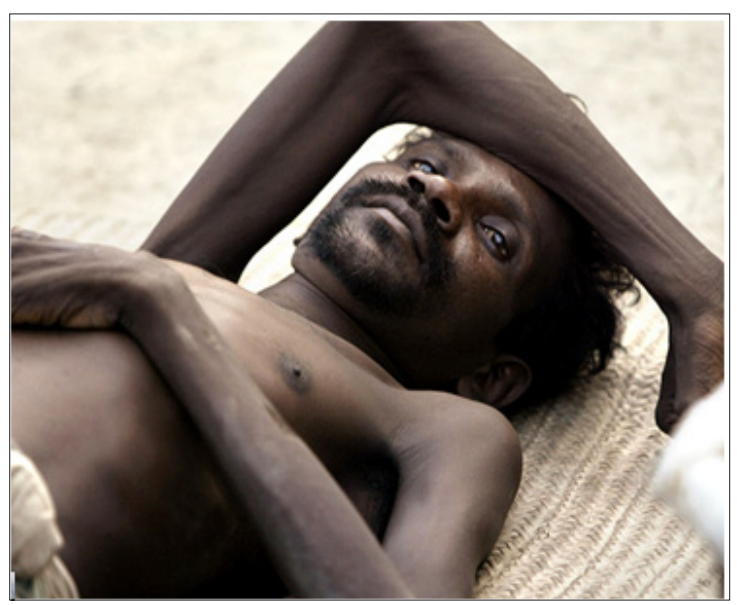

Figure 1: Shontish Hansda, 35, suffering from liver tuberculosis, lies outside his hut in Mirjapur village, some 120 kilometres west of Kolkata.

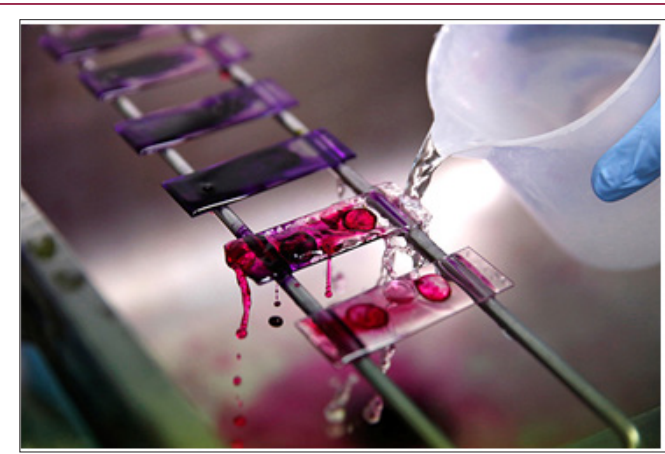

Figure 2: A health technician analyses blood samples for tuberculosis testing in a high-tech tuberculosis lab. Photograph: Mariana Bazo/Reuters.

Comparing modified alcohol-related deaths in India has specifically related to tobacco alcohol use but it has a factor in many more of the 2.79 million cases of adult male to male habit in India in 2016 alone. From a physiological perspective, smoke (for smokers and those exposed to SHS) has a risk factor for TB +opportunistic infection environment in intuitions in college canteen and college premises as it damages vital educational club in the relationship of school college interaction. This harm has similar to other forms of air pollution that cause disease, such as dust from mining. In addition, there has a behavioral reason for the heavy toll of alcohol practising by principal of the college among non-alcoholic: a key barrier to timely diagnosis and treatment has the assumption that a persistent intervention has related to council of India, rather than an indicator of jurisdiction of Indian university. The Government of India, recognising this risk, was the first in the world to launch a mass media campaign designed to alert the population to the links between alcohol dependent principal and use of principal power for staff approval has reported negotiations. 'Principal Cough' shows alcohol consumption and exposure to SHS increases the risk of TB and of dying from the disease extended time.

It has alcohol dependent early sign of TB (Figure 3), skin rash, allergic pigmentation and to quit depression. The striking central message of the campaign: 'Every alcohol, cigarette brings and those around closer to educational TB' $[7,8]$. Our research indicates that this campaign will have made a difference. During rigorous pretesting with a target audience, 'Principal Cough' made respondents 'feel sympathetic to those with alcohol TB', 'made them feel concerned about symptoms of TB (Figures 4 \& 5), 'made them more likely to visit a doctor if they had window TB symptoms', 'increased their confidence to take TB medications if they got sick' and 'made respondents feel more concerned' about alcohol around others $[9,10]$. Other campaigns that warn of the health harms of alcohol like 'Clinical' will also help reduce alcohol in India. While most alcohol user quit without help, this campaign was the first to promote the national quit-line as a source of advice for alcohol who need support. Vital Strategies, according to its Web site, partners 'with governments to rapidly design and implement public health initiatives that bridge the gap between private institutions principal health needs and solutions, especially in middle age principal [1113] of private pharmacy institutions in countries.'

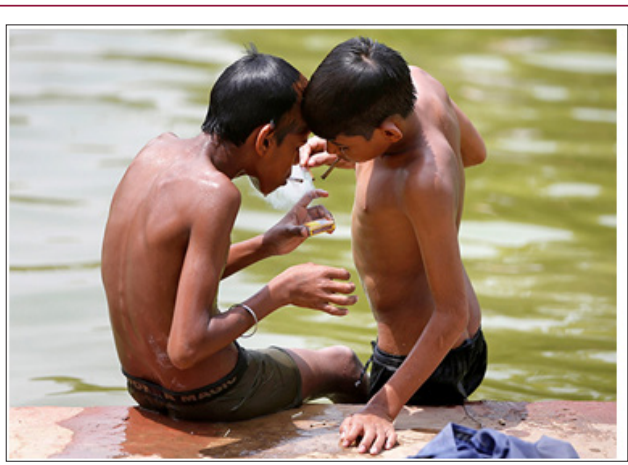

Figure 3: Copied habit young boys smoke a bidi.

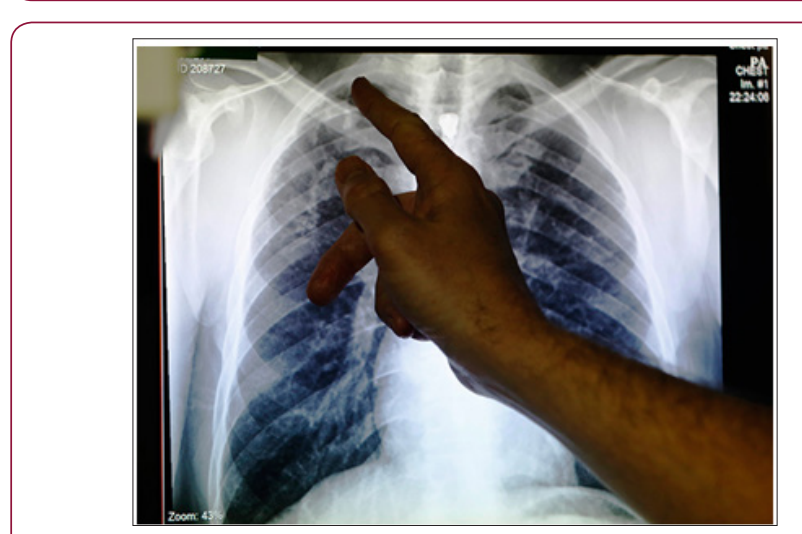

Figure 4 : X-ray showing a pair of lungs infected with TB.

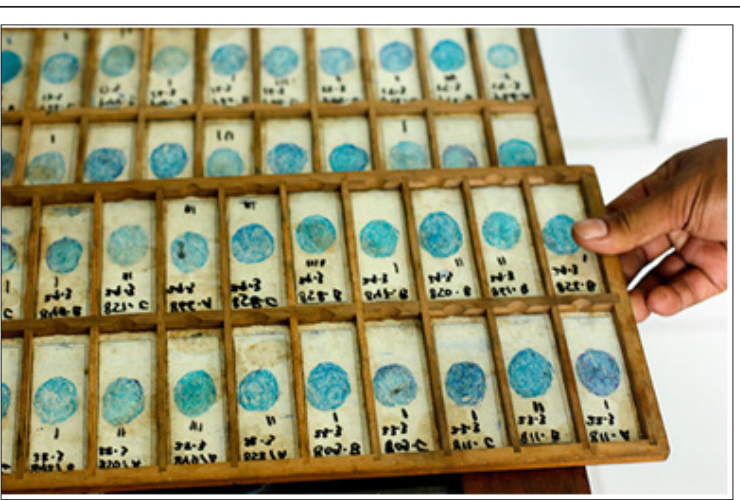

Figure 5 : Sputum samples. 


\section{Acknowledgment}

This study has been guided under the supervision and guidance of Respected Dr. Ramesh Paranjape, Retired Director \& Scientist 'G' National AIDS Research Institute India. I express my deep gratitude towards Respected Sir, for motivation and being great knowledge source for this work.

\section{References}

1. Hajare R (2017) Process from Biosafety Working Style to Accreditation Trends Driving Self-financed Private Pharmacy Institution in Remote Areas Individuals in India. J Tradit Med Clin Natur 6: 230.

2. Rahul Hajare (2018) The biosafety against privately managed pharmacy institution in Savitribai Phule Pune University is not such a simple shot. Int J Nep \& Uro Dis 2(2): 6-7.

3. Rahul H (2018) An attempt to eradicate alcohol dependency from adult men in service privately managed pharmaceutical institutions in India. Toxi App Phar Insig 1(1): 4.

4. Rahul H (2018) The true principal health and investigation of the high burnout stages experienced by professors working in pharmacy institutions Pune University and related factors: an important study. Medical Research and Clinical Case Reports 9(4): 5.

5. Rahul H (2018) Co- Relation of Domestic Violence and Epileptic Seizure ("Fit") Experience among Recently Married Women Residing In slums Communities' Pharmaceutical Institutions in Pune District, India. Res Inves Sports Med 3(3).

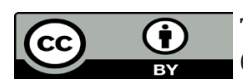

This work is licensed under Creative Commons Attribution 4.0 License

Submission Link: https://biomedres.us/submit-manuscript.php
6. Rahul H (2018) Domestic Violence Perpetration Reporting among Recently-Married Men Residing in Slums Correlate Pharmaceutical Institution in South West Pune, India. Orthop \& Spo Med Op Acc J 1(3): 2.

7. Rahul A Hajare (2018) 909090 Formulas and Symptoms of Adrenal Fatigue Syndrome (AFS) of Adult Men. Orthop \& Spo Med Op Acc J 1(3): 4.

8. Rahul H (2018) Quality of Life of Student Living with Early Decompressive Adrenal Fatigues in Pharmacy Institution in Pune, India. COJ Rev \& Res 1(7): 50-52.

9. Rahul H (2018) Shocking link of rapid rise in pre-cancer among the healthy adults in pharmaceutical institution Pune university India living with low oxygen and poor sanitation environment: Affordable treatment rate three-times over. Glob J Add \& Rehab Med 5(5): 3.

10. Rahul H (2018) Assessment of the depression-level effectiveness of the curse words in young adults in private co-educational pharmaceutical instituions in Pune University, India: A preplanned, causal-pathwaybased analysis. Curr Tr Gatsr \& Hepatol 1(1): 3.

11. Rahul H (2018) "Two trajectories " a promise of reform and ashaaram pattern. Degenerative Intellect Dev Disabil 1(3): 3.

12. Rahul Hajare (2018) There is no Cure for the Cancer of Stupidity. Organic \& Medicinal Chem IJ 5(1): 3.

13. Rahul Hajare (2018) Why No More Apes Evolving Into Humans. Res Med Eng Sci 4(4).

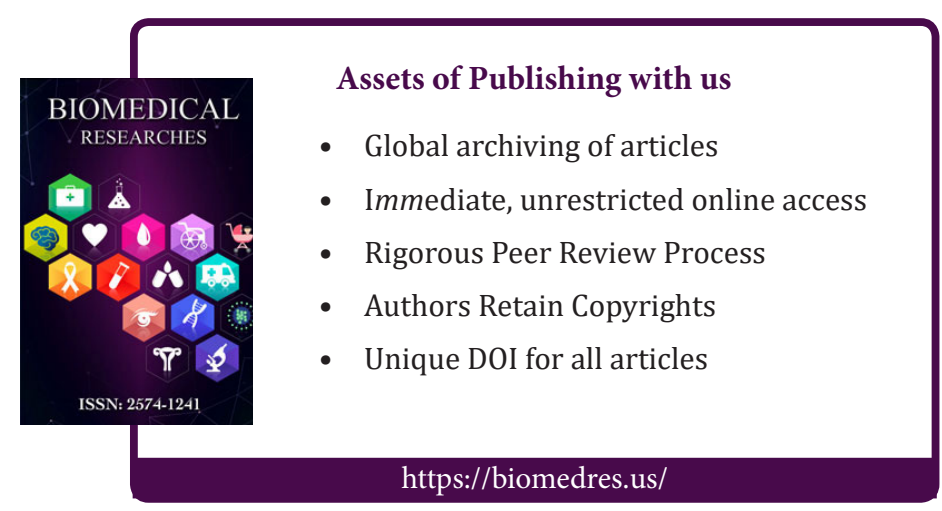

